Chapter 1

Children in Institutional Care:

Delayed Development and Resilience 


\section{Children in Institutional Care: Delayed Development and Resilience}

Children exposed to institutional care do not receive the type of nurturing and stimulating environment needed for normal growth and healthy psychological development. This chapter is devoted to the analysis of the ill effects of early institutional experiences. The chapter starts with a description of the nature of institutional care, exemplified by the case of a specific, well-documented institution for young children. A summary of the typical delays and deviations in the development of institutionalized children is then presented. The concept of "post-institutional syndrome" is discussed, with an analysis of the foundations and the implications of the concept. Since not all children exposed to similar institutional circumstances develop in a similar way, the final section is devoted to a consideration of the heterogeneity of outcomes, as well as to an analysis of resilience and protection mechanisms.

\section{The Nature of Institutional Care}

The institutional care of abandoned and orphaned children is widely used in countries with different ethnic, cultural, and economic backgrounds, and its nature may vary not only between but also within countries. Ideally, an analysis of the nature of institutional care would be based on systematic assessments of those environments; however, such assessments are rare. With a few significant exceptions (e.g., Groark, McCall, Fish, \& The Whole Child International Team, 2009; Groark, Muhamedrahimov, Palmov, Nikiforova, \& McCall, 2005; The St. Petersburg-USA Orphanage Research Team, 2005;Vorria, Papaligoura, Dunn, van IJzendoorn, Steele, Kontopoulou, \& Sarafidou, 2003), most reports include only brief first- or second-hand narrative impressions and perceptions. Although there is considerable consistency among these accounts, there are also conflicting reports. On the basis of such accounts, Gunnar (2001) classified institutions into three levels, based on the quality of care they provide: (1) institutions characterized by global deprivation of the child's health, nutrition, stimulation, and relationship needs; (2) institutions with adequate health and 
nutrition support, but deprivation of the child's stimulation and relationship needs; and (3) institutions that meet all needs except for stable, long-term relationships with consistent caregivers. Logically it is possible to add a fourth level, namely an institutional environment that provides for stable and consistent caregiving, and only deprives children of a regular family life embedded in a regular social environment. Promoting such an institution might be considered the ultimate goal of some institutional intervention efforts (e.g., The St.

Petersburg-USA Orphanage Research Team, 2005, 2008).

Despite the variability in care that can be found among institutions, it is possible to put together a composite description of what is typical. The following narrative is not a report of a particular institution but rather combines various accounts to give the reader a better sense of what is common amidst considerable heterogeneity in institutional care

- Group sizes tend to be large (typically 9-16 children per ward, although in extreme cases the number may approach 70). The number of children per caregiver is large (approximately 8:1 to 31:1, although a few institutions have fewer children per caregiver).

- Most institutions have homogeneous groups with respect to ages and disability status. Children are periodically "graduated" from one age group to another perhaps as many as two or three times in the first two or three years of life.

- Caregivers for any single child tend to change constantly because there may be a high staff turnover; caregivers may work long shifts (e.g., 24 hours) and be off three days; caregivers may not be consistently assigned to the same group; and caregivers may get up to two months vacation. The result is that a child may see anywhere from 50 to 100 different caregivers in the first 19 months of life. 
- Other adults tend to come and go in children's lives, including medical and behavioral specialists, prospective adoptive parents, and volunteers who may visit for only a week or a few months.

- Caregivers likely receive little training, and the training they do receive is more focused on health issues than on social interaction. They spend the vast majority of their hours feeding, changing, bathing, cleaning children and the room, and preparing food rather than interacting with the children. Caregivers are invariably female, so children rarely see men.

- When caregivers perform their caregiving duties, it is likely to be in a business-like manner with little warmth, sensitivity, or responsiveness to individual children's emotional needs or exploratory initiatives.

The Metera Babies Center (MBC), in Athens (Greece) is a specific example of institutional rearing that is characterized by many of the features described above. MBC was originally established to protect and support unmarried mothers and their infants. Over time it became a residential care setting for about 100 infants, providing them with accommodation and care 24 hours per day, 7 days per week until they are placed with adoptive, foster, or biological parents. A special unit exists for newborns, and approximately 5 months after birth these infants are moved to pavilions housing children ranging in age from five months to five years. The vast majority of the children are adopted or fostered by the age of two-and-a-half to three years, with some also returning to their biological families. A small number of children remain in the institution until the age of five, either because their parents do not allow them to be adopted or fostered or because they have serious developmental or physical problems. Most infants are at high risk for neglect or abuse when they enter the institution, and have been abandoned or relinquished by their parents during the first few days after birth 
because they were unable to provide for them. The large majority are "social orphans" rather than "true" orphans (i.e., without parents).

MBC provides adequate nutrition and health care but lacks a playful and cognitively stimulating environment and stability in child-caregiver relationships. In MBC, the most depriving period is the first few months of life. In the special unit for newborns the social contacts and interactions are very restricted. Each newborn is placed in a separate small room alone. One caregiver is responsible for as many as seven infants, which is why caregivers limit their attention to feeding and cleaning the babies. Subsequently, when the babies move to the pavilions, they are housed in groups of 12 children who are looked after by 12 caregivers in total. Thus, in theory the infant/caregiver ratio is $1: 1$, but in practice, due to the 24-hour shifts, the real ratio ranges from 4:1 to 6:1, because each caregiver has to look after four to six infants at the same time. During weekends and holidays even fewer caregivers are available to look after the infants. Although books and toys are available in MBC wards for somewhat older children, the caregivers do not have enough time to interact with the infants using these materials in a stimulating way.

According to the MBC daily time schedule, on a regular day infants spend a total of $3 \frac{1}{2}$ hours playing and $171 / 2$ hours in their beds; the remaining time is taken up with feeding and cleaning. Apart from the problems caused by understaffing, many of the caregivers are not adequately trained for their jobs and their interactions with the infants are less sensitive than those of biological mothers in a comparison group of family-reared infants, even in optimal conditions, such as when the caregiver is interacting with only one child (Vorria et al., 2003). Applying the Early Childhood Environment Rating Scale (ECERS; Harms \& Clifford, 1980) developed for group care, MBC provides an extremely low quality of care in all domains of child rearing (personal care, furnishing, language - reasoning experiences, fine and gross motor activities, creative activities, social development, and adult needs) compared 
to child care centers in various countries (Vorria et al., 2003), a result found for orphanages in St. Petersburg(Russian Federation; The St. Petersburg-USA Orphanage Research Team, 2005) and three Latin American orphanages(Groark et al., 2009).

Both MBC and the "prototypical" institution described above inevitably deprive children of sensitive reciprocal interactions with stable caregivers. In this respect, many if not most institutions can be characterized as having structural neglect, which may include minimum physical resources, unfavorable staffing patterns, and socially-emotionally inadequate caregiver-child interactions, which collectively may be considered a special case of child maltreatment.

\section{Delays and Deviations in Institutionalized Children's Development}

Children raised in institutions often suffer from dramatic developmental delays and may follow deviant developmental pathways. However, the various causes of these delays are difficult to disentangle. First, in some instances it is difficult to know whether the institutional experience actually causes the deficits or simply maintains pre-existing deficits. Second, the forms of deprivation experienced by institutionalized children rarely occur in isolation from one another. Here we briefly present the (often severe) developmental deficiencies that most institution-reared children display. We selected to concentrate on the important areas of physical, hormonal, cognitive, and emotional development for which replicated evidence exists, this does not constitute a complete picture. A range of other delays, deviations, and disorders have been observed in children in the post-institutional period which almost certainly had their roots during institutional care (see Chapters 5, 6, 9).

\section{Physical Growth}

Children who spend the first few years of their lives in institutional care often show retarded physical growth (Van IJzendoorn, Bakermans-Kranenburg, \& Juffer, 2007; Chapter 3). Institutionalized children lag behind their family-reared peers on such central parameters 
of physical growth as weight, height, and head circumference. For example, in a metaanalysis of eight studies ( $N=893$ institution-reared children), longer institutional stays were strongly and linearly associated with a more delayed age-corrected growth in height $(r=.62$; $d=1.71$ ), which points to a dose-response relation, illustrating the potentially causal, negative effect institutional care on physical growth, and in particular on height. This metaanalytic finding is supported by longitudinal studies on growth within institutions in Greece (Vorria et al., 2003, see Van IJzendoorn \& Juffer, 2006) and in Ukraine (Dobrova-Krol, van IJzendoorn, Bakermans-Kranenburg, Cyr, \& Juffer 2008) (see also chapter 2).

\section{Hormonal (HPA Axis) Development}

Atypical patterns of diurnal cortisol activity for children living in institutions were first reported by Carlson and Earls (1997). They examined 46 children, aged 2 years, who lived in an institution in Romania. Most had been there since shortly after birth. Not one of the children exhibited a normal pattern of cortisol variation over the day ( 8 am, noon, $7 \mathrm{pm}$ ), with low early morning and slightly elevated evening values being the norm in this sample. This finding was replicated in a very small sample of children, half adopted from Russia and half from China (Gunnar, 2001). Another study conducted in a Russian Baby Home with 11 children at 3 to 5 months of age produced similar results of blunted rhythms of diurnal cortisol production (Kroupina, Gunnar, \& Johnson, 1997, cited in Gunnar, 2000).

To study the effect of institutional rearing on diurnal cortisol production, DobrovaKrol et al. (2008) examined 16 institution-reared children (3 to 6 years old) from Ukraine and compared them with 18 local family-reared children pair-matched on age and gender. Diurnal salivary cortisol was sampled 6 times during one day. Almost one-third of institution-reared children were chronically and severely delayed or "stunted" in their physical growth, whereas none of the family-reared children were. Institutionally-reared and family-reared children showed similar patterns of diurnal cortisol production with decreases over the day. However, 
non-stunted institutionally-reared children had a significantly higher total daily cortisol production than both chronically stunted institution-reared children and family-reared children. The chronically stunted children had suffered from perinatal hypoxic conditions and underwent a treatment to stabilize the functioning of the nervous system involving diazepam as well as corticosteroids (Edelstein, Bondarenko, \& Bykova, n.d.), which could have had a lasting effect on the HPA-axis functioning of these children. All groups demonstrated a normal diurnal pattern with elevated morning cortisol values and subsequent decline during the day. The discrepancy with previous findings (Carlson \& Earls, 1997; Kroupina et al., 1997) may be explained by the older age of the children in the Ukraine study, and may be also due to the differentiation between stunted and non-stunted children.

As yet, we have little or no data to evaluate whether alterations in growth or neuroendocrine activity as measured while children are in institutional care or shortly after adoption mediate any of the cognitive and emotional effects noted for post-institutionalized children (see Chapters 2, 3, 4).

\section{Cognitive Development}

The cognitive development of institutionalized children has been studied for more than 60 years. Between 1930 and 1950 a first wave of studies documented that children in institutions often showed a low IQ and severe language delays (Crissey, 1937; Durfee \& Wolf, 1933), and children's orphanages have been considered "natural experiments" on the necessary conditions for intellectual growth (MacLean, 2003). Recent research continues to show the delayed cognitive performance of children in residential care (Ahmad \& Mohamad, 1996; Sparling, Dragomir, Ramey, \& Florescu, 2005; Vorria et al., 2003; Zeanah, Smyke, Koga, \& Carlson, 2005), although in one study increases in cognitive development with longer stay in the institution was noted (The St. Petersburg-USA Orphanage Research Team, 2008). 
In a recent meta-analysis, children growing up in institutions showed a substantial delay in IQ compared with children reared in (foster or biological) families (van IJzendoorn, Luijk, \& Juffer, 2008). The combined effect size in 75 studies on more than 3,800 children in 19 different countries was about three-quarters of a standard deviation. For most samples, absolute IQ/DQ scores were available. The children reared in institutions showed on average an IQ/DQ of 84; the average IQ/DQ of comparison children raised in families was 104. Favorable caregiver-child ratios were associated with smaller cognitive delays, whereas early entry into residential care (before 12 months) and thus longer stays seemed to be associated with larger delays. One or more years of family life may provide a (relatively) firm basis for further intellectual development even when children grow up in a poor intellectual environment later on.

In the unique randomized control Bucharest Early Intervention Project (BEIP, Nelson et al., 2007), young children living in institutions were randomly assigned to continued institutional care or to placement in foster care, and their cognitive development was tracked through 54 months of age. The authors report three main findings confirming the metaanalytic findings on non-randomized trials. First, children reared in institutions showed greatly diminished intellectual performance (borderline mental retardation) relative to children reared in their families of origin. Second, children randomly assigned to foster care experienced significant gains in cognitive function. Lastly, the younger a child is when placed in foster care, the better the cognitive outcome. Indeed, there was a continuing "cost" to children who remained in the institution for longer periods of time (see Chapter 6 on sensitive periods).

\section{Attachment Security}

Institution-reared children all experience separation from or loss of their birth parents and other caregivers. In a famous report for the World Health Organization on institutions, 
Bowlby (1952) concluded that children suffered from the effects of institutional care, even when their physical needs (food, clothes, etc.) were adequately met. The children are deprived of opportunities to develop stable and continuous attachment relationships due to the limited amount and poor quality of contact with their caregivers (Gunnar, Bruce, \& Grotevant, 2000; Palacios \& Sánchez-Sandoval, 2005; Vorria et al., 2003; Zeanah et al., 2005).

Six recent studies addressed the effects of institutional care on attachment, using the Strange Situation Procedure (SSP; Ainsworth et al., 1978) or a modification, and institutionalized children showed high rates of insecure attachment and especially high rates of disorganized attachment (Dobrova-Krol et al., in preparation; The St. Petersburg-USA Orphanage Research Team, 2008; Vorria et al., 2003; Zeanah, Smyke, Koga, \& Carlson, 2005; Steele, Steele, Jin, Archer, \& Herreros, 2009; Herreros, 2009). Overall, the attachment status distribution of institution-reared children deviated markedly from the typical distribution (62\% secure, $15 \%$ avoidant, $9 \%$ resistant, and 15\% disorganized; van IJzendoorn et al., 1999), with $17.1 \%$ secure, $5.5 \%$ avoidant, $4.6 \%$ resistant, and $72.8 \%$ disorganized attachments to the favorite caregiver. In fact almost three-quarters of the institution-reared children were classified as disorganized.

The higher rate of disorganized attachment in an institutional environment of structural neglect compared to that in family-reared normative groups was to be expected. Compared to the effects of child maltreatment within the family on attachment disorganization, the percentage of secure attachments is somewhat higher in the institutionreared children (maltreated children: 14\%) but the percentage of disorganized attachments is considerably larger (maltreated children: $51 \%$, as derived from Cyr, Euser, BakermansKranenburg, \& van IJzendoorn, in press). Whether attachment classifications, in particular disorganized attachments, mean the same in an institution as in a regular family environment 
remains to be discussed (Rutter et al., 2009; Zeanah et al., 2005; Chapter 3). The wide variety of attachment outcomes within institutions, from extremely disorganized to secure, is puzzling in view of the fact that all children went through the same kind of institutional ordeal in a sensitive stage of their development. This heterogeneity is discussed in the next section.

\section{A Post-Institutional Syndrome?}

As shown in the previous sections, patterns of problems experienced by children growing up in institutions take a somewhat specific form. These include delayed physical growth and brain development, dysregulation of the neuroendocrine systems, delayed cognitive development, and deviant attachment and/or attachment disorder, to mention just a few domains of dysfunction. This begs the question whether it is useful to speak of an "Institutionalization Syndrome" to characterize the problems experienced by institutionalized children or to use the term "Post-Institutionalized" when children move from institutions to foster or adoptive families.

According to the DSM-IV (American Psychiatric Association, 1994, p. 771), three elements are necessary to identify a syndrome: 1) A group of signs and symptoms, 2) their frequent co-occurrence, and 3) a common underlying pathogenesis, course, familial pattern, or treatment selection. In the alleged "post-institutionalization syndrome", the third putative element is obviously present in that all children have been exposed to institutional rearing early in life. The presence of the other two criteria needs further consideration.

In the DSM system, the decision regarding the existence of a given condition is typically based on the presence of a critical number of features. In the case of "conduct disorder," for instance, at least three out of 15 symptoms need to be present, with at least one present in the last six months. Although, according to MacLean (2003), there is no area in which orphanage children remain unscathed, from what we know about the development of 
institution-reared children, it is unclear whether delays in all of the domains need to be present to speak of a syndrome or if, for the same purpose, a combination of certain problems is more critical than a combination of others.

Two additional problems are known in developmental psychopathology as equifinality and multifinality, and both are present in the development of postinstitutionalized (PI) children. Equifinality refers to the fact that the same end-state may be reached from a variety of initial conditions (Cicchetti \& Rogosch, 1996). Some emotional or behavioral problems considered to be typical of PI children have also been reported in children who have been abused or maltreated by their families (Cicchetti \& Toth, 2005). Similarly, the disturbances associated with attachment in PI children are also found in children without the experience of institutional life (O'Connor \& Zeanah, 2003). Obviously, a low IQ can be found in children with an array of developmental circumstances. It would then be perfectly possible to find a child who was never institutionalized but who presents some kind of growth problems, attention difficulties, attachment disorder, and low intelligence similar to a post-institutionalized child. However, some outcomes may be more specific to PI children from severely deprived backgrounds (e.g., disinhibited attachment and quasi-autism; Chapter 3).

Multifinality refers to the fact that a particular adverse event (in our case, the early experience of institutional rearing) should not be seen as necessarily leading to the same outcomes in each individual (Cicchetti \& Rogosch, 1996), due to non-shared institutional effects and child related resilience mechanisms. Two children with a similar amount of exposure in the same institution can end up with very different developmental profiles, from profound maladaptation to normal functioning (e.g., Beckett et al., 2006). Institutional deprivation appears to have probabilistic rather than deterministic influences on children's difficulties. 


\section{Does a Group of Symptoms Co-Occur in PI Children?}

According to the DSM-IV definition, the co-occurrence of symptoms is another defining characteristic of a syndrome. Are there symptoms that tend to co-occur because of the experience of orphanage life?

It is not easy to derive an answer to this simple question from the extant studies. Even when research on PI children is concerned with several areas (growth, intelligence, behavioral problems, attachment difficulties), the results usually remain disconnected. This might be due to the fact that researchers are mainly interested in the epidemiology of a problem, that is, comparing PI children with children in the general population. Also, on other occasions, researchers are interested in the developmental trajectory of a given characteristic (for example, what is the IQ at age 10 of those adopted as infants from an orphanage?), and pay no attention to other developmental domains.

For a cluster of symptoms to be identified in the same individual, the approach would need to be more clinical than epidemiological and several areas would need to be covered simultaneously. So far, most of the analyses are at the level of between-group differences (e.g., institutional care below and above 6 months), providing little information about the cooccurrence of the symptoms. The study by Kreppner et al. (2007), exploring at once seven psychological domains, is one of the first attempts to analyze the co-occurrence of impaired functioning in the same individuals, although most of the statistically significant differences refer only to the number of impairments. This study suggests that, among the children with several impairments, a deprivation-specific pattern of cognitive deficits, quasi-autism and disinhibited attachment can be identified. More recent analyses of the age 15 data in the English Romanian Adoptees study suggests the existence of a significant but incomplete degree of overlap between these different patterns suggesting a degree of commonality to children's responses to severe deprivation (Rutter and Sonuga-Barke, 2010; Kumsta, 
Kreppner, Rutter, Beckett, Castle, Stevens and Sonuga-Barke, 2010). This pattern of findings needs to be replicated in independent, less extremely deprived samples before a broader "post-institutionalization syndrome" concept could be supported.

\section{Risks of a "Post-Institutional Syndrome" Concept}

Apart from the empirical question, identifying a "post-institutional syndrome" as a concept may be inadvisable. According to Pennington (2002), naming a syndrome can confer a false sense of validity on the diagnostic category and the impression that there is an explanation for the deviant behavior. The idea that a name provides an explanation is called the "nominal fallacy."

The risks of this fallacy can be illustrated by an example. The early onset of puberty has been described as one of the symptoms of PI children, with the speculation that circumstances of early severe deprivation produce significant alterations in the hypothalamic systems regulating food intake, physical growth, and the biology of puberty (Gunnar, 2001). Although not all adopted children have been exposed to institutional rearing (and not all of those exposed were in the institution for the same length of time or under similar circumstances), recent Danish data show that the risk of developing precocious puberty significantly increased by 10 to 20 times in adopted girls compared with girls with a Danish background (Teilman et al., 2006). If precocious puberty was one of the symptoms listed under the "PI syndrome," then the nominal fallacy would suggest that the deprivations suffered in the institution are the cause of the early onset of puberty via damage to the appropriate brain structures (see chapter 2). However, the evidence shows that, out of 11,000 adopted children in the Danish sample, only 655 (around 6\%) developed precocious puberty, with children from some regions (e.g., South America, India) being at much higher risk and children from other regions at no risk (e.g., South Korea). Also, there is evidence showing that both genetic and prenatal factors (poor intrauterine growth) are implied (Mul et al., 2002; 
Teilman et al., 2006; Chapter 2). These pre-institutional factors could interact with the depriving orphanage circumstances, thus increasing the risk, but not necessarily causing it.

The other risk with the concept of a PI syndrome is stigmatization. In 1978, the concept of "Adopted Child Syndrome" was introduced by Kirschner to refer to a form of conduct disorder presumably connected to an adoptive status. Behaviors would include conflict with authority, preoccupation with excessive fantasy, pathological lying, stealing, running away from home or school, learning difficulties, lack of impulse control (acting out, promiscuity, sex crimes), and a fascination with fire or fire-lighting. The main difference from other conduct disorders would be the link to adoption-related dynamics, such as unresolved issues around the birth parents' rejection, fantasies about the birth parents, and identity difficulties. Although initially endorsed by some clinicians and researchers, the concept of "Adopted Child Syndrome" was later abandoned following criticism of its conceptual and methodological flaws (e.g., Smith, 2001).

The concept of the adopted child syndrome originated within the context of a clinical practice in which adopted persons were over-represented. When the focus of the research moved from clinical to community samples, the perception of adopted persons became more positive and adoption was seen as protection rather than as risk (Palacios \& Brodzinsky, 2005), and indeed adoption is now more often perceived as a successful intervention that leads to remarkable catch-up in all domains of child development (Van IJzendoorn \& Juffer, 2006). Adopted persons are a very heterogeneous group and the vast majority seems to be able to function well within normal ranges of behavior and development. In these circumstances, the concept of an adoption-related syndrome would not justify this evidence and would create a negative image which is of little help to the adoptees, to the professionals working with them, to their parents, and to the community as a whole. 
The same could happen with PI children. If we take one of the well-documented areas of inquiry, externalizing problems, it is true that the proportion of PI children scoring in the clinical-borderline range is higher than in the general population of children (Juffer \& Van IJzendoorn, 2005). According to Merz and McCall (in press), whereas in the general population of children $15 \%$ are in the clinical-borderline range of externalizing problems, the percentage of PI in this range is $35 \%$ for children from globally deprived institutions and around 20\% for children from less deprived institutional circumstances (see Chapter 9). With $65 \%$ (globally deprived institutionalization) or $80 \%$ (more favorable institutional circumstances) of PI children not showing elevated externalizing scores, the use of a label that negatively unifies the heterogeneity and ignores the diversity of circumstances seems neither advisable nor helpful.

The less well-defined and substantiated a syndrome is, the more advisable it seems to avoid the risk of generalization and self-fulfillment. If, based on weak evidence, a syndrome is defined as characteristic of children who have been in institutions and if a child has been institutionalized, then there may be a tendency to interpret some normal behaviors in accordance with the syndrome. The risk of a friendly, ex-institutional child being labeled as disinhibited or of an active child with not very good attention skills being characterized as inattentive/hyperactive, is the type of stigmatization worth avoiding.

\section{An Alternative}

An alternative to the idea of a PI syndrome would be to return to the concept of institutional maltreatment, in particular structural neglect.

As it was defined by Gil (1982), institutional maltreatment refers to acts and policies of commission or omission that inhibit or insufficiently promote the development of children or that deprive or fail to provide them with the material, emotional, and symbolic means needed for their normal development. Structural neglect is probably the main and more 
widespread form of institutional maltreatment, pointing to the fact that, by their arrangement and form of operation, institutions fail to respond to some of the children's basic needs for stable and positive personal relationships as well as for adequate care and stimulation. As a common background for the problems observed in post-institutional children, the concept of structural neglect is fruitful, because it identifies the cause more than its potential consequences, adds less burden to the victims, and points to a reality that can and should be changed if the needs of the children are to be met in a "good-enough" manner. Also, as discussed previously, some of the consequences of institutional rearing are shared by other forms of child maltreatment, which may provide a wider conceptual framework for understanding some formerly institutionalized children's problems and their solutions.

Whether or not the concept of post-institutional syndrome is supported by the data, a deeper analysis of the observed heterogeneity among PI children is definitely needed. This concerns the type, degree, and overlap of impairment(s); the diversity of institutional effects; and the child-related resilience mechanisms in the face of the institutional adversity. These issues are discussed in the next section.

\section{Resilience and Protection}

Heterogeneity in terms of both degree and type of impairment and/or disorder is a hallmark of the developmental outcomes of children who experienced early institutionalization. In terms of degree, children suffering to all intents and purposes the same exposures to adverse environments, can end up with very different levels of impairment and dysfunction. For some, extended institutionalization can lead to profound impairment and/or mental disorders. Others who have spent the same length of time in the same institutions can function quite normally and be indistinguishable from their non-institutionalized peers. 
Further, individuals showing impairment and dysfunction can be affected in different ways across a wide variety of intellectual, inter-personal and behavioral domains. In some cases outcomes may be quite specific: For instance, problems of attention and activity are frequently reported in children who have suffered early institutional deprivation (Stevens et al., 2008). For some children, these may be part of a complex of problems involving low IQ, attachment problems, and impairments in inter-personal relationships (Kreppner et al., 2008). However, for others, these additional domains may be completely unaffected. While heterogeneity is marked, the degree of variation in outcome is not unconstrained. This is best illustrated in relation to the duration of deprivation experienced. It is very unusual for exposure of only a few months to cause problems of significance assuming normal liability, whereas in the case of extended periods or even permanent institutionalization outcomes are likely to be invariably poor.

Given this, the study of the factors that may account for this diversity, by moderating the paths between risk and disorder, represents a vital stage in the development of both scientific understanding and improved clinical care. In terms of exposure to, and impact of, deprivation-related risks within institutions, there are shared and non-shared institutional effects that need to be considered, together with resilience mechanisms operating within the child that need to be specified.

Shared institutional effect. Are there characteristics of particular institutions that place children in general at risk or alternatively common factors that ameliorate deprivationrelated risks?

There are likely to be general factors of significance that relate to the regime of an institution and their levels of care-provision for the children. The overall quality of institutional care is likely to play a key role in determining outcomes. Therefore, we would expect that children in institutions with more and better food, more staff, and greater levels of 
personalized care and social and cognitive stimulation are likely to fare better and those with the obverse to fare worse.

However, the relative importance of these different elements of provision is not known. Could provision in one key area override the damaging effects of other elements of the risk of institutions? Would, for instance, a plentiful and nutritious diet offset the deleterious effects of severe and chronic social deprivation? A recent analysis of the relative contributions of sub-nutrition and duration of deprivation across multiple outcome domains suggests that this is not the case (Sonuga-Barke et al., 2008). While there are effects of subnutrition on some domains (most obviously IQ), residual effects of duration of deprivation were found in a well nourished group even in these domains. A good diet was not enough to counter a bad social environment. In this study the quality of care in terms of social interaction and intellectual stimulation in institutions was not directly measured so we do not know whether shared institutional enhancements in these areas may have protective potential and override the effects of poor diet on IQ. Within institution intervention studies seem to support the significance of socio-emotional features. These studies have varied from highly structured, somewhat artificial additional sensory or perceptual experiences to attempts to change the entire institutional behavioral climate, promote more stability and consistency in caregivers, and encourage warm, sensitive, and responsive caregiver-child interactions. The latter interventions are the most comprehensive (e.g., The St. Petersburg-USA Orphanage Research Team, 2008; see also Smyke at el., 2002, Sparling et al., 2005), and are implemented by ordinary orphanage staff, and they seem to produce the most developmental improvement in children in both physical and behavioral domains (but see BakermansKranenburg et al., 2008, for some caveats).

Non-shared institutional effects. Non-shared institutional effects are either due to chance or at least arbitrary events of a positive (or negative) nature that occur independently 
of the characteristics of the child or are due in some way to those characteristics and the way they elicit a particular sequence of events. For the former we can think of a child being placed under the care of a particularly kind or considerate caregiver, and for the latter we can think of a child with a particular demonstrative and demanding nature who may get more attention and care than a quiet and reserved child. Unfortunately, by their very nature these effects operate on a micro level in idiosyncratic and individualistic ways and are therefore hard to study empirically. However, more generic hypotheses about the role of physical attractiveness or temperamental reactivity could be tested.

Child-related resilience mechanism. Children may elicit, either through active engagement or some feature of their personality or appearance, a response from their environment that might protect them from deprivation-related risk either by reducing their exposure to risk factors or altering their impact once they have been exposed. In addition to these child-led effects, child-based genetic factors may operate to reduce or increase the vulnerability of a particular child to risk in general (i.e., general hardiness genes), to institutional deprivation generally, and to the effects of institutional deprivation on specific outcomes. The evidence that genetic factors can moderate pathways between social risk and developmental outcome is growing (e.g., Caspi et al., 2003).

How might we investigate genetic moderation of the effects of early deprivation? The most direct way to test for genetic effects is to look at markers of genes that either 1) confer risk for a specific disorder outcome common in populations exposed to institutional deprivation or 2) might alter the response to the risk factor more generally (Stevens et al., 2006).

In terms of the first strategy genes of potential functional significance with regard to activity of dopamine (e.g., DAT1, DRD4, DRD2, see Bakermans-Kranenburg \& van IJzendoorn, 2009) and serotonin (5HTT) systems look especially interesting candidates. 
Initial studies provide evidence for genotype $\mathrm{x}$ duration of institutional deprivation interactions implicating both the DAT1 10R/10R (for ADHD; Stevens et al., 2009) and the 5HTT-LPR L/L genotype (for emotional problems; Kumsta et al., in press). In terms of the second strategy, a number of candidate classes of genes can be identified. One possible model implicates the stress reactivity systems and argues that early adversity in institutional setting may reprogram brain-stress systems. For instance, laboratory and clinical studies implicate polymorphisms within glucocorticoid receptor genes in determining individual differences in biological stress reactivity and the level of cortisol response to different stressful situations. However, initial exploration of the role genotypic variations in these genes does not support a genetic stress moderation hypothesis (Kumsta et al., in press).

Generally there are a number of plausible mechanisms that might account for genetic moderation of environmental risk. For example genetic factors may 'block' the exposure of children to, or determine their degree of sensitivity to, deprivation-related risk. Genetic factors may reduce the receptivity of children to the experience of adversity (this is the differential susceptibility hypothesis based on genetic factors; Belsky, BakermansKranenburg, \& Van IJzendoorn, 2007). A second class of explanations focuses more on the possibility that high-risk environments alter the expression or effect of genes. Perhaps adverse social environments may switch-off or socially benign environments switch-on genetic effects through epigenetic mechanisms such as DNA methylation (Mill \& Petronis, 2008). While not much is known empirically about the power of early deprivation that impinges on gene expression within humans (but see Meaney et al. (2009) recent suicide paper for a powerful exception), recent animal models suggest that such effects are plausible (Parent et al., 2005; Diorio \& Meany, 2007). 


\section{Conclusions}

Children in institutional care show delays and maladaptation in various domains of development, but not every child is affected in the same way and to the same degree. At present there are insufficient empirical grounds to use the concept of a post-institutional syndrome. Children from institutions should not be labeled with a psychiatric diagnosis that would by applied to all children. At the same time, the institutional setting itself is in most cases pathogenic and should be classified as a type of child maltreatment, particularly in the form of structural neglect. Although most institutions even in modern times create a childrearing environment best typified by structural neglect, some children remain resilient even in the most adverse settings. Shared and non-shared features of the institutional environment and specific genetic, temperamental, and physical characteristics of the individual child might make a crucial difference in whether or not the orphanage leaves irreversible scars. It is important to study the interaction between the children and their institutional environment at a micro-level, taking into account individual hardiness and vulnerabilities at the genetic or temperamental level as well as strengths and weaknesses of the specific child-rearing setting. A closer look at the interactions of resilient children with various facets of the institutional environment may provide insight into ways to improve institutional life for all or most children involved. 


\section{References}

Ahmad, A., \& Mohamad, K. (1996). The socioemotional development of orphans in orphanages and traditional foster care in Iraqi Kurdistan. Child Abuse and Neglect, $20,1161-1173$.

Ainsworth, M.D.S., Blehar, M.C., Waters, E., \& Wall, S. (1978). Patterns of attachment: A psychological study of the strange situation, Hillsdale, NJ, Erlbaum.

American Psychiatric Association (1994). Diagnostic and statistical manual of mental disorders (4th ed.). Washington, DC: Author.

Bakermans-Kranenburg, M.J. \& Van IJzendoorn, M.H. (2007). Genetic vulnerability or differential susceptibility in child development: The case of attachment. Journal of Child Psychology and Psychiatry, 48 (12), 1160-1173.

Bakermans-Kranenburg, M. J., \& van IJzendoorn, M. H., Juffer, F. (2008). Earlier is better: A meta-analysis of 70 years of intervention improving cognitive development in institutionalized children. Monographs of the Society for Research in Child Development, 73, 279-293.

Beckett, C., Maughan, B., Rutter, M., Castle, J., Colvert, E., Groothues, C., et al. (2006). Do the effects of early severe deprivation on cognition persist into early adolescence? Findings from the english and romanian adoptees study. Child Development, 77, 696711.

Belsky, J., Bakermans-Kranenburg, M. J., \& van IJzendoorn, M. H. (2007). For better and for worse: Differential susceptibility to environmental influences. Current Directions in Psychological Science, 16, 300-304.

Bowlby, J. (1952). Maternal care and mental health. Geneva: World Health Organization. 
Carlson, M., \& Earls, F. (1997). Psychological and neuroendocrinological sequelae of early social deprivation in institutionalized children in Romania. Annual New York Academy of Science, 807, 419-428.

Caspi, A., Sugden, K., Moffitt, T. E., Taylor, A., Craig, I. W., Harrington, H., et al. (2003). Influence of life stress on depression: Moderation by a polymorphism in the 5-htt gene. Science, 301, 386-389.

Cicchetti, D., \& Rogosch, F. A. (1996). Equifinality and multifinality in developmental psychopathology. Development and Psychopathology, 8, 597-600.

Cicchetti, D., \& Toth, S. L. (2005). Child maltreatment. Annual Review of Clinical Psychology, 1, 409-438.

Crissey, O. L. (1937). The mental development of children of the same IQ in differing institutional environments. Child Development, 8, 217-220.

Cyr, C.A., Euser, E.M., Bakermans-Kranenburg, M.J., \& Van IJzendoorn, M.H. (in press). Attachment insecurity and disorganisation in maltreating and high-risk families: A series of meta-analyses. Development and Psychopathology.

Diorio, J., \& Meaney, M. J. (2007). Maternal programming of defensive responses through sustained effects on gene expression. Journal of Psychiatry \& Neuroscience, 32, 275284.

Dobrova-Krol, N.A., Van IJzendoorn, M.H., Bakermans-Kranenburg, M.J., \& Juffer, F., Cyr Ch. (2008). Physical Growth Delays and Stress Dysregulation in Stunted and NonStunted Ukrainian Institution-Reared Children. Infant Behavior and Development, 31, $539-553$.

Dobrova-Krol, N.A., Van IJzendoorn, M.H., Bakermans-Kranenburg, M.J., \& Juffer, F. (in prep.). The Importance of Quality of Care: Effects of Perinatal HIV-infection and 
Early Institutional Rearing on Preschoolers' Attachment and Indiscriminate Friendliness.

Durfee, H., \& Wolf, K. (1933). Anstaltspflege und Entwicklung im ersten Lebensjahr. Zeitschrift fur Kinderforschung, 42, 3, 272-320.

Edelstein, E.E., Bondarenko, E.S., \& Bykova, L.I., (n.d.). Perinatal Hypoxic Neurological Syndromes. Retrieved May 8, 2007, from http://www.russianadoption.org/Encephalopathy.htm

Gil, E. (1982). Institutional abuse of children in out-of-home care', Child and Youth Care Review, 4, 7-13.

Groark, C. J., McCall. R. B., Fish, L.A., and The Whole Child International Team (2009). Characteristics of environments, caregivers, and children in three Latin American orphanages. Pittsburgh, PA: University of Pittsburgh Office of Child Development.

Groark, C. J., Muhamedrahimov, R. J., Palmov, O. I., Nikiforova, N. V., \& McCall, R. B. (2005). Improvements in early care in Russian orphanages and their relationship to observed behaviors. Infant Mental Health Journal, 26, (2), 96-109.

Gunnar, M. R. (2000). Early adversity and the development of stress reactivity and regulation. In C.A. Nelson (Ed). The effects of adversity on neurobehavioral development. The Minnesota Symposia on Child Psychology, Vol.31, (pp 163-200). Mahwah, NJ: Lawrence Erlbaum.

Gunnar, M. R. (2001). Effects of early deprivation. In C. A. Nelson \& M. Luciana (Eds.), Handbook of developmental cognitive neuroscience, (pp. 617-629). Cambridge, MA: MIT Press.

Gunnar, M. R., Bruce, J., \& Grotevant, H. D. (2000). International adoption of institutionally reared children: Research and policy. Development and Psychopathology, 12, 677693. 
Harms, T., \& Clifford, R.M. (1980). Early Childhood Environment Rating Scale. NY: Teachers' College Press.

Herreros, F. (2009). Attachment Security of Infants Living in a Chilean Orphanage. Poster presented at the Biennial Meeting of the Society for Research in Child Development, Denver, U.S.A.

Kreppner, J. M., Rutter, M., Beckett, C., Castle, J., Colvert, E., Groothues, C.,, Hawkins A, O’Connor TG, Stevens S, Sonuga-Barke EJS (2007): Normality an impairment following profound early institutional deprivation: A longitudinal follow-up into early adolescence. Developmental Psychology, 43(4), 931-946.

Kumsta, R., Stevens, S., Schlotz, W., Castle, J., Beckett, C., Kreppner, J., Rutter, M., \& Sonuga-Barke, E.J.S. (in press). 5HTT genotype moderates the influence of early institutional deprivation on emotional problems in adolescence: evidence from the English and Romanian Adoptee (ERA) study. Journal of Child Psychology \& Psychiatry.

Kumsta R, Kreppner J., Rutter, M., Beckett C., Castle J., Stevens S., \& Sonuga-Barke, E. J. S. (2010, in press). Deprivation-specific psychological patterns. In Rutter, M., Sonuga-Barke, E.J. (Eds.) \& The English and Romanian Adoptees Study Team. Deprivation-specific psychological patterns: Effects of institutional deprivation. Monographs of the Society for Research in Child Development.

MacLean, K. (2003). The impact of institutionalization on child development. Development and Psychopathology, 15, 853-884.

McGowan, P.O., Sasaki, A., D'Alessio, A.C., Dymov, S., Labonté, B., Szyf, M., Turecki, G., Meaney, M.J.(2009). Epigenetic regulation of the glucocorticoid receptor in human brain associates with childhood abuse. Nature Neuroscience,12(3), 342-348. 
Merz, E. C., \& McCall, R. B. (in press). Behavior problems in children adopted from socially-emotionally depriving institutions. Journal of Abnormal Child Psychology.

Mill, J., \& Petronis, A. (2008). Pre- and peri-natal environmental risks for attention-deficit hyperactivity disorder (ADHD): the potential role of epigenetic processes in mediating susceptibility. Journal of Child Psychology and Psychiatry, 49, 1020-1030

Mul, D., Oostdijk, W., \& Drop, S. L. S. (2002). Early puberty in adopted children. Hormone Research, 57(1-2), 1-9.

O’Connor, T.G., \& Zeanah, C.H. (2003). Introduction to the Special Issue: Current Perspectives on Assessment and Treatment of Attachment Disorders. Attachment and Human Development, 5, 221-222.

Palacios, J., \& Brodzinsky, D. (2005). Recent changes and future directions for adoption research. In D. Brodzinsky \& J. Palacios (Eds.), Psychological issues in adoption. Research and practice (pp. 255-266).Westport, CT: Praeger.

Palacios, J., \& Sánchez-Sandoval, Y. (2005). Beyond adopted/non-adopted comparisons. In D. Brodzinsky \& J. Palacios (Eds.), Psychological issues in adoption: Research and applications (pp. 115-142).Westport, CT: Greenwood.

Pennington, B.F. (2002). The development of psychopathology. Nature and nurture. New York: Guildford Press.

Rosas, J., \& McCall, R. B. (2009). Characteristics of institutions, interventions, and resident children's development. Unpublished manuscript, authors. Pittsburgh, PA: University of Pittsburgh Office of Child Development.

Rutter, M., Kreppner, J., \& Sonuga-Barke, E. (2009). Emanuel miller lecture: Attachment insecurity, disinhibited attachment, and attachment disorders: Where do research findings leave the concepts? Journal of Child Psychology and Psychiatry, 50, 529543. 
Smith, J. (2001). The Adopted Child Syndrome: A methodological perspective. Families in society, $82,491-497$

Smyke, A. T., Dumitrescu, A., \& Zeanah, C. H. (2002). Attachment disturbances in young children. I: The continuum of caretaking casualty. Journal of the American Academy of Child and Adolescent Psychiatry, 41, 972-982.

Sonuga-Barke, E. J. S., Beckett, C., Kreppner, J., Castle, J., Colvert, E., Stevens, S., et al. (2008). Is sub-nutrition necessary for a poor outcome following early institutional deprivation? Developmental Medicine and Child Neurology, 50, 664-671.

Sparling, J., Dragomir, C., Ramey, S. L., \& Florescu, L. (2005). An educational intervention improves developmental progress of young children in a Romanian orphanage. Infant Mental Health Journal, 26, (2), 127-142.

Steele, M., Steele, H., Jin, X., Archer, M. \& Herreros, F. (2009). Effects of lessening the level of deprivation in Chinese orphanage settings: Decreasing disorganization and increasing security. Paper presented at the Biennial Meeting of the Society for Research in Child Development, Denver, U.S.A.

Stevens, S. E., Sonuga-Barke, E. J. S., Kreppner, J. M., Beckett, C., Castle, J., Colvert, E., Castle, J., Groothues, C., Hawkins, A., \& Rutter, M. (2008). Inattention/overactivity following early severe institutional deprivation: Presentation and associations in early adolescence. Journal of Abnormal Child Psychology, 36(3), 385-398.

Stevens S, Kumsta R, Kreppner J, Brookes K, Rutter M, Sonuga-Barke EJS (2009).

Dopamine transporter gene polymorphism moderates the effects of severe deprivation on ADHD symptoms: Developmental continuities in gene-environment interplay. American Journal of Medical Genetics Part B: Neuropsychiatric Genetics, 150B, $753-761$.

Teilmann, G., Main, K., \& Skakkebaek, N.. (2002). High frequency of central 
Precocious puberty in adoptee and immigrant children in Denmark. Hormonal Research. 58:135.

The St. Petersburg - USA Orphanage Research Team (2005). Characteristics of children, caregivers, and orphanages for young children in St. Petersburg, Russian Federation. Applied Developmental Psychology, 26, 477-506.

The St. Petersburg - USA Orphanage Research Team (2008). The effects of early socialemotional and relationship experience on the development of young orphanage children. Monographs of the Society for Research in Child Development. 73, 1-262.

Van IJzendoorn, M. H., Luijk, M., \& Juffer, F. (2008). IQ of children growing up in children's homes: A meta-analysis on IQ delays in orphanages. Merrill-Palmer Quarterly-Journal of Developmental Psychology, 54, 341-366.

Van IJzendoorn, M.H., \& Juffer, F. (2006). The Emanuel Miller Memorial Lecture 2006. Adoption as intervention. Meta-analytic evidence for massive catch-up and plasticity in physical, socio-emotional, and cognitive development. Journal of Child Psychology and Psychiatry, 47, 1228-1245.

Van IJzendoorn, M.H., Bakermans-Kranenburg, M.J., \& Juffer, F. (2007). Plasticity of growth in height, weight and head circumference: Meta-analytic evidence of massive catch-up of children's physical growth after adoption. Journal of Developmental and Behavioral Pediatrics, 28, 334-343.

Van IJzendoorn, M.H., Schuengel, C., \& Bakermans-Kranenburg, M.J. (1999). Disorganized attachment in early childhood: Meta-analysis of precursors, concomitants, and sequelae, Development and Psychopathology, 11, 225-249.

Vorria, P., Papaligoura, Z., Dunn, J., van IJzendoorn, M. H., Steele, H., Kontopoulou, A., \& Sarafidou, J. (2003). Early experiences and attachment relationships of Greek infants 
raised in residential group care. Journal of Child Psychology and Psychiatry, 44, 1208-1220.

Zeanah, C.H., Smyke, A.T., Koga, S., Carlson, E. \& the BEIP Core Group (2005). Attachment in institutionalized and community children in Romania. Child Development, 76, 1015-1028. 